\title{
Iliac fossa block is useful for postoperative analgesia of total hip arthroplasty
}

\author{
Yuya MURATA ${ }^{1}$, Shinichi INOMATA ${ }^{2}$, Keiichi TAJIMA ${ }^{3}$, Shigeyuki SAITO ${ }^{4}$, Makoto TANAKA ${ }^{2}$ \\ ${ }^{1}$ University of Tsukuba Hospital, Dept of Anaesthesiology, Tsukuba, Japan, ${ }^{2}$ University of Tsukuba, Dept of Anaesthesiology, Tsukuba, Japan, \\ ${ }^{3}$ Tsukuba Memorial Hospital, Dept of Anaesthesiology, Tsukuba, Japan, ${ }^{4}$ Tsukuba Gakuen Hospital, Dept of Anaesthesiology, Tsukuba, Japan
}

\begin{abstract}
Background : Benefit of combined regional anesthesia during lower-extremity joint operation under general anesthesia have been reported ${ }^{1)}$. Conversely, regional anesthesia including a peripheral nerve block presents a risk of nerve injury ${ }^{2}$. Here we examined new type of compartment block; iliac fossa block we named, in which a medicinal solution is injected into a site distant from the nerve. To ensure whether this "iliac fossa block" is useful for postoperative analgesia, we conducted a prospective-observational study that we investigated the requirements of fentanyl in intravenous patient-controlled analgesia (IV-PCA).

What is iliac fossa block?

Like an ilioinguinal-iliohypogastric nerve block, the block needle is placed at a site that is around the outer quarter of a line connecting the anterior superior iliac spine and the umbilicus (Figure 1), then punctured in the direction of the iliac bone, penetrating the abdominal transverse muscles. The needle's point is advanced into the iliac muscle in front of the iliac bone (Figure 2), and then after a negative aspiration test we inject the local anesthetic at this site. Like a conventional fascia iliaca compartment block, the iliac fossa block can block the lateral femoral cutaneous nerve, the femoral nerve and the obturator nerve. In addition, because of the local anesthetic spread to the central side, the block can be expected to act on the lumbar plexus.
\end{abstract}

\section{Methods}

> Subject of this study: Adult patients who were confirmed to undergo total hip arthroplasty (THA) under general anesthesia

> Exclusion criteria : Patients who were contraindicated for regional anesthesia or had neurological disorders, diabetes mellitus, less than $33 \mathrm{~kg}$ in body weight

- Anesthesia : General anesthesia at the discretion of each anesthesiologist, but opioids are only fentanyl and remifentanil

$>$ Block: In the iliac fossa block group (Group B), $40 \mathrm{ml}$ of $0.25 \%$ ropivacaine was injected under ultrasound-guidance with a liner probe $(6-13 \mathrm{~Hz})$ after the induction of anesthesia (Figure 1,2)

$>$ Control : In the control group (Group C), the block was not used

$>$ IV-PCA : Fentanyl (base: $10 \mu \mathrm{g} / \mathrm{h}$, bolus dose: $10 \mu \mathrm{g}$, lockout time: 5 minutes)

$>$ Outcome : The amount of fentanyl used during each surgery, the requirements of fentanyl as IV-PCA up to $48 \mathrm{hr}$ post-surgery and the block area by cold test after awaking of the patient

$>$ Data and Statistics: The values were mean \pm standard deviation, $p<0.05$ was considered as significant (unpaired t-test or Chisquared test)

Results

$>$ Demographic data and Patient characteristics are shown in Table 1.

$>$ As for intraoperative dose of fentanyl, there was no significant difference between the two groups (Table 1).

- The cumulative fentanyl requirements at $24 \mathrm{~h}$ postoperatively were significantly less in Group B than Group C; $274 \pm 46 \mu \mathrm{g}$ vs. $468 \pm 305 \mu \mathrm{g}(\mathrm{p}=0.03)$, at $48 \mathrm{~h}$ were no significant difference; $557 \pm 138 \mu \mathrm{g} v \mathrm{vs} .788 \pm 405 \mu \mathrm{g}(\mathrm{p}=0.05)$ (Figure 3 ).

$>$ In the fentanyl requirements from $24 \mathrm{~h}$ to $48 \mathrm{~h}$ postoperatively, there was no significantly between the two groups (Figure 3 ).

$>$ The success rate of the block in cold test was $50 \%$ in the lateral femoral cutaneous nerve, $40 \%$ in the femoral nerve and $20 \%$ in the obturator nerve.

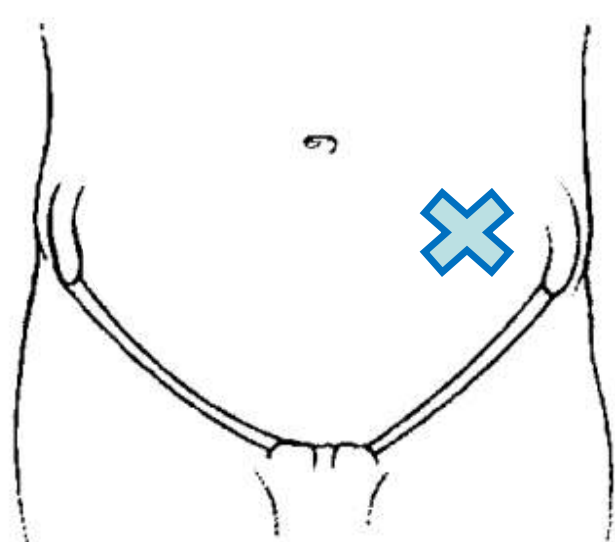

Figure 1. Puncture positon in iliac fossa block (left side)

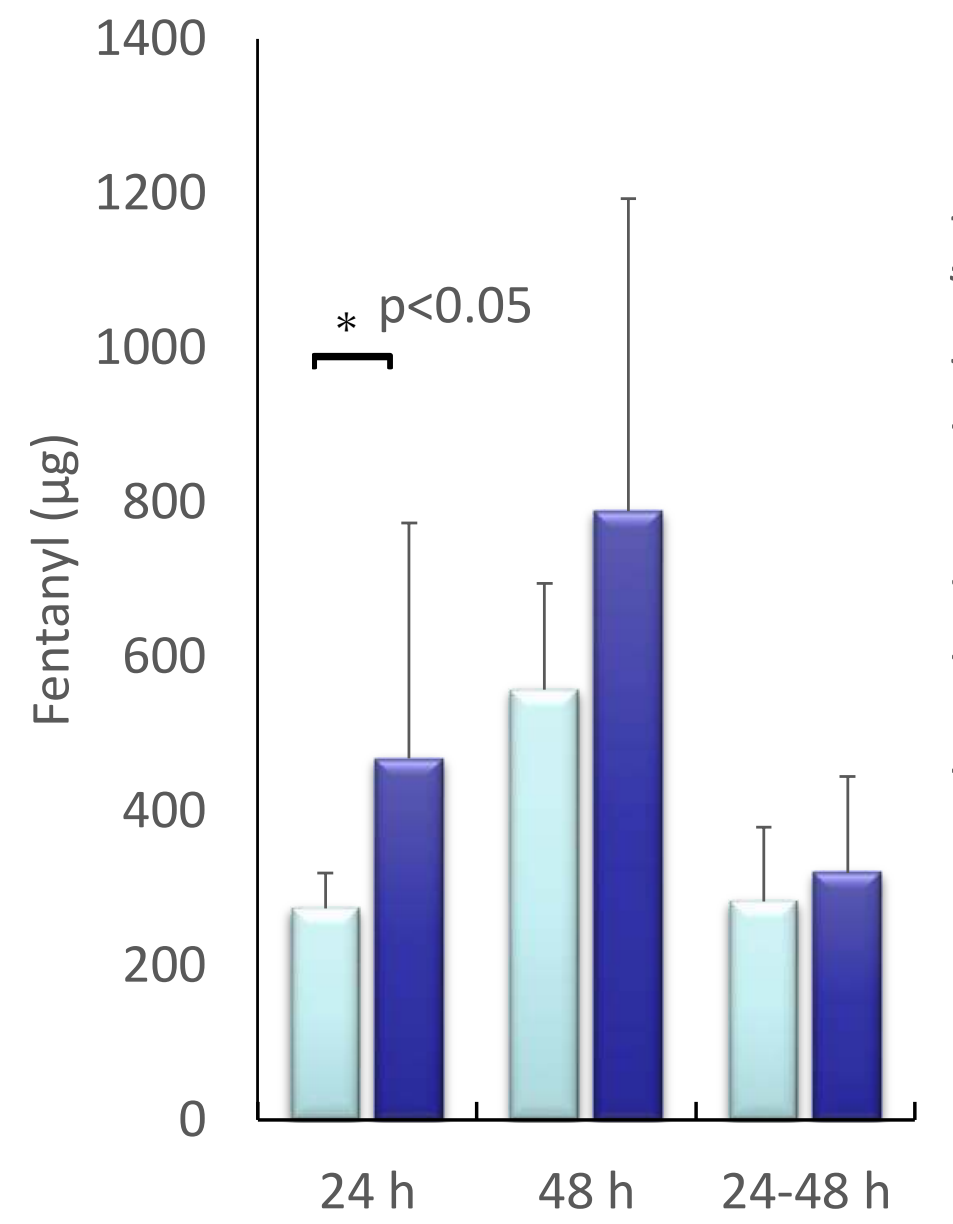

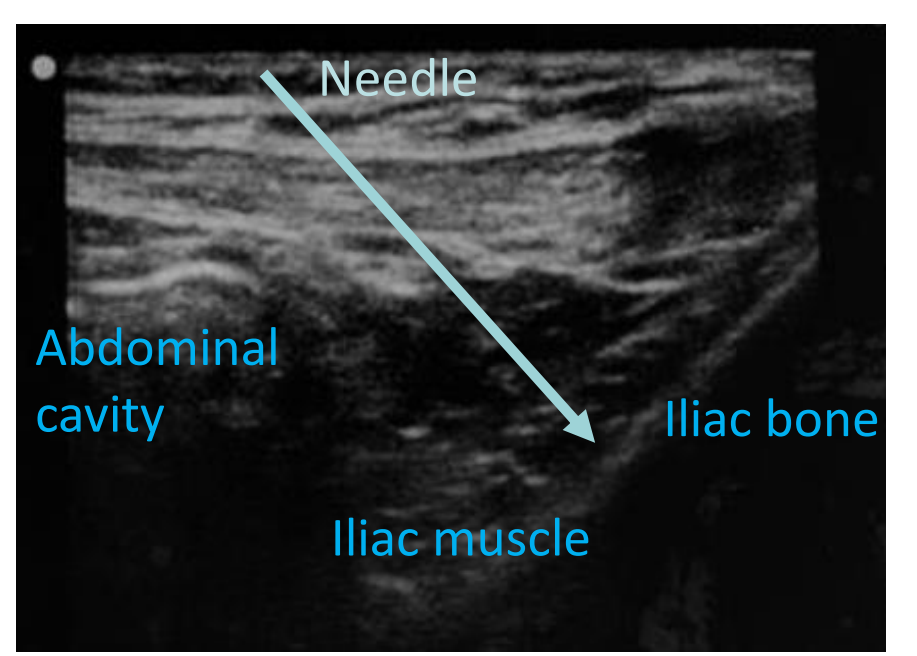

Figure 2. Echo image (left side)

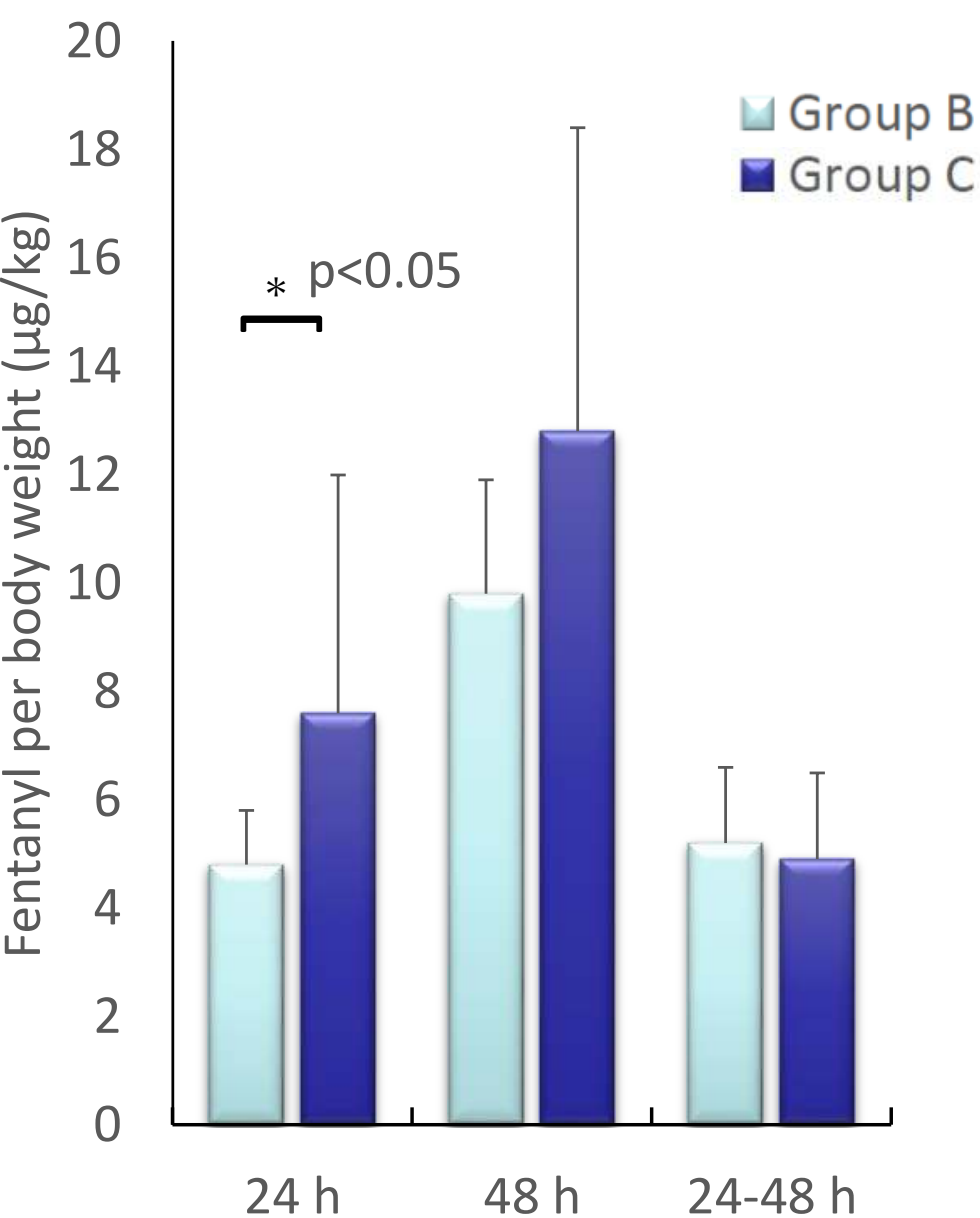

Figure 3. Postoperative fentanyl requirements

Table 1. Demographic data and Patient characteristics

\begin{tabular}{lccc}
\hline & Group B (n=10) & Group C (n=13) & P value \\
\hline Age (year) & $61 \pm 12$ & $60 \pm 13$ & 0.46 \\
Sex (male/female) & $1 / 9$ & $5 / 8$ & $<0.01$ \\
Height $(\mathrm{cm})$ & $155 \pm 6$ & $158 \pm 9$ & 0.17 \\
Body weight $(\mathrm{kg})$ & $58 \pm 11$ & $61 \pm 9$ & 0.25 \\
BMI $\left(\mathrm{kg} / \mathrm{m}^{2}\right)$ & $24 \pm 5$ & $25 \pm 3$ & 0.47 \\
Surgical site (right/left) & $3 / 7$ & $6 / 7$ & 0.44 \\
Surgical time (minute) & $123 \pm 43$ & $91 \pm 19$ & 0.01 \\
Anesthesia time (minute) & $209 \pm 53$ & $165 \pm 31$ & 0.01 \\
Blood loss (ml) & $332 \pm 225$ & $273 \pm 286$ & 0.30 \\
Intraoperative dose of fentanyl $(\mu \mathrm{g})$ & $208 \pm 80$ & $242 \pm 61$ & 0.12 \\
Intraoperative dose of fentanyl per body weight $(\mu \mathrm{g} / \mathrm{kg})$ & $4 \pm 2$ & $4 \pm 1$ & 0.29 \\
\hline Values are expres
\end{tabular}

Values are expressed as the mean \pm standard deviation or number

$\mathrm{n}$ : number of patients, BMI : Body Mass Index

Conclusion : The postoperative fentanyl requirements were significantly less in the iliac fossa block group, and this block was useful for the postoperative analgesia of THA.

We have no conflict of interest to declare.

\section{References}

1) Memtsoudis SG et al. The impact of peripheral nerve blocks on perioperative outcome in hip and knee arthroplasty-a population-based study. Pain 2016;157:2341-2349

2) Auroy $Y$ et al. Major complications of regional anesthesia in France. Anesthesiology 2002;97:1274-1280 